\title{
INFLUENCE OF A LOW TEMPERATURE AGEING ON THE PROPERTIES OF AL-6.5\%SI-0.35\%MG ALLOY
}

\author{
O. B. Umaru1, ${ }^{*}$, M. Abdulwahab ${ }^{2}$, N. M. Hafsat ${ }^{3}$, H. Maidawa ${ }^{4}$, A. 0. Murtada ${ }^{5}$ and T. M. Suleiman ${ }^{6}$ \\ 1,3,45,6Dept. of Mechanical/Production EnG'G, Abubakar TafaWa BaleWa UniV. Bauchi, Bauchi State, NiGERIA \\ 2 Department of Metallurgical and Materials Engr., Ahmadu Bello Univ., Zaria, Kaduna State, NiGERIA \\ E-mail addresses.1 okatengwubello@yahoo.com, ${ }^{2}$ koladejp@yahoo.com, ${ }^{3}$ hnmomoh@atbu.edu.ng, \\ 4hmaidawa82@gmail.com, 5 smurtada99@gmail.com,6smatahir41@gmail.com
}

\begin{abstract}
The effect of a low temperature ageing treatment on the hardness, tensile and corrosion characteristics of sand cast Al-6.5\%Si-0.35\% Mg alloy was studied. The temper conditions are low temperature ageing at $90^{\circ} \mathrm{C}, 95^{\circ} \mathrm{C}, 100{ }^{\circ} \mathrm{Cand}$ $105^{\circ} \mathrm{C}$ respectively followed by ageing to $180^{\circ} \mathrm{C}$ for $2 \mathrm{hrs}$. This was compared with the control sample which was aged directly to $180^{\circ} \mathrm{C}$ for $2 \mathrm{hrs}$. The hardness of the Al-6.5\%Si-0.35\%Mg alloy was measured using the RockwellHRB scale hardness tester, while the tensile characteristic was evaluated using a graphical tensometer. The corrosion resistance of the alloy was evaluated using weight loss analysis in simulated sea water environment. An increase in the hardness characteristic was observed in the low temperature ageing at $90^{\circ} \mathrm{C}(7.8 \mathrm{HRB})$ as compared with (6.0 HRB) that was obtained for the control. From the tensile results obtained, the extension value for the control samples was $(1.4 \mathrm{~mm})$ while the sample with a low temperature ageing of $105^{\circ} \mathrm{C}$ gave the highest extension of $(2.26 \mathrm{~mm})$. Remarkable decrease in corrosion rate was observed at $95^{\circ} \mathrm{C}\left(2.3373 \mathrm{~mm} / \mathrm{yr} \times 10^{-7}\right)$ as compared with the control of (5.2049 mm/yr x10-7). From the Optical Microscope (OPM) and Scanning electron microscope (SEM) results, it was observed that the microstructures were refined for low temperature ageing when compared with the control samples. From these results, it can be deduced that the low temperature ageing treatment had an appreciable influence on the properties of this alloy.
\end{abstract}

Keywords: low temperature aging, aluminum alloys, corrosion resistance, one-step ageing, elemental sodium

\section{INTRODUCTION}

Foundry Aluminum alloys based on the Al-Si alloys are widely used in the automobile industries because of their excellent fluidity, cast ability, good resistance to corrosion and mechanical properties [1]. Al-Si alloys comprise $85 \%$ to $90 \%$ of the total aluminum cast alloys and it dominates the automotive field and market with up to $75 \%$ in the form of castings [2]. The solid solution strengthener is obtained in Aluminum alloys by adding $\mathrm{Mg}$ to $\mathrm{Al}-\mathrm{Si}$ based alloys which also provide the precipitation hardening $(\mathrm{PH})$ in order to yield high strength [3]. Al-6.5\%Si-0.35\%Mg alloy shows response to heat treatment [4] and increase strength by precipitation of $\mathrm{Mg}_{2} \mathrm{Si}$ in aluminum matrix [1].

The addition of alloying elements to the alloy improves its mechanical properties but its corrosion resistance may sometimes be reduced due to precipitation of these elements along the grain boundaries after ageing [5-6]. Though certain alloying elements can simultaneously improve strength and corrosion resistance [6], the $\mathrm{Al}-6.5 \% \mathrm{Si}-0.35 \% \mathrm{Mg}$ alloy produced is widely used in automobile, aerospace and other applications because of its high strength to weight ratio and good corrosion resistance [6-8]. However, Al-6.5\%Si-0.35\% Mg alloy has low elastic modulus and precipitation hardening response in the T6 temper; Solution Heat Treatment (SHT) and artificial ageing conditions $[1,5]$. Experiments have shown that ageing for a sufficient time at temperature above about $150^{\circ} \mathrm{C}$ significantly increase the resistance to corrosion, but reduced strength/hardness in the T6 temper condition of the alloys as a result of coarsening of precipitates [5-6]. One-step ageing (Single Thermal Ageing Treatment; STAT-T6) of Al-6.5\%Si-0.35\%Mg alloy have been

* Corresponding author, tel: +234-703-600-0632 
reported in several studies in the T6 temper condition (SHT + artificial ageing) $[1,6]$. For the purpose of this study a low temperature ageing treatment (varying temperatures that are less than the ageing treatment for stabilization) was developed.

\section{MATERIALS AND METHOD}

\subsection{Materials and equipment}

The materials that was used in this research include; aluminum cable wires obtained from NOCACO company, Kaduna-Nigeria, Aluminum-Silicon ligand, silicon powder $(\mathrm{Si})$, magnesium ribbon $(\mathrm{Mg})$, distilled water, elemental sodium and charcoal. Some of the equipment used include charcoal fired crucible furnace, stirring rod, crucible pot, split metal mould, slag scooper, pair of tongue, Muffle electrical resistance furnace (used for the heat treatment with capacity of $1200^{\circ} \mathrm{C}$ ), INDENTEC Universal H.T.M (Model 8187.5LKV (B)), Metallurgical microscope, lathe machine (turning and facing), torrent lathe machine (semi automatic machine), hacksaw, file, vernier caliper, polishing machine and Hounsfield Tensometer (Serial no. w3179).

\subsection{Casting of the samples}

The Al-Si-Mg alloy with charge calculation as presented in Table 1 was produced in this work. The mould was prepared by pouring sand which was mixed with binder in the cape and the drag, the cavities of the bar intended to be produced was formed in the cape and drag. Aluminium scraps was first charged into the furnace and was heated to a temperature above the melting point of aluminum ( $>$ $700^{\circ} \mathrm{C}$ ) to ensure that the wire melts completely. The Aluminium-copper ligand was then charged into the crucible and was also allowed to melt after heating for some time. The magnesium ribbon was then added and the molten composition was stirred using a stirring rod. The slag formed was removed using slag scooper and then elemental sodium $(0.01 \% \mathrm{Na})$ was then added and stirred thoroughly before pouring into the produced mould.

Table 1: Charge calculation of the produced alloy

\begin{tabular}{lcccc}
\hline Element & $\mathrm{Al}$ & $\mathrm{Si}$ & $\mathrm{Mg}$ & $\mathrm{Na}$ \\
\hline Percentage composition & 91.9 & 6.5 & 0.3 & 0.01 \\
\hline
\end{tabular}

\subsection{Machining of the produced alloy}

The operations carried out on the as cast include facing, parallel turning using both lathe machine and torrent lathe machine then the specimens was cut using hacksaw and filed using smooth file.

\subsection{Solution heat treatment of the alloy}

Samples for hardness, corrosion and tensile test were solution heat treated to a temperature of $540^{\circ} \mathrm{C}$ for 1 hour in an electrical heat treatment furnace and then rapidly quenched in water at room temperature. The quenched samples then underwent low temperature ageing of $90^{\circ} \mathrm{C}, 95^{\circ} \mathrm{C}, 100^{\circ} \mathrm{C}$ and $105^{\circ} \mathrm{C}$ and a conventional ageing as described below.

\subsection{Conventional ageing treatment (control)}

The samples were aged at $180^{\circ} \mathrm{C}$ for 2 hours and used as the control samples.

\subsection{Low temperature ageing treatment}

Samples were given a low temperature ageing treatment by pre-ageing at temperatures of $90^{\circ} \mathrm{C}$, $95^{\circ} \mathrm{C}, 100^{\circ} \mathrm{C}$ and $105^{\circ} \mathrm{C}$ respectively and finally ageing to $180^{\circ} \mathrm{C}$ for 2 hours.

\subsection{Hardness measurement}

Hardness test was conducted on the samples comprising of low temperature ageing and conventional ageing treatment. The anvil of the Rockwell hardness-B scale tester was properly cleaned before the samples was place and well supported to prevent any movement during the test, since any slight movement can significantly alter the hardness results. The hand wheel was smoothly rotated clockwise to uplift the anvil until the sample made a contact with the indenter. The hand wheel was further rotated slowly and smoothly until the cursor reaches the end position, where a buzzing warning was given out indicating that the rotation should be stopped at once and the hardness values was recorded.

\subsection{Tensile Test}

The specimen of dimension ( $6 \mathrm{~mm}$ diameter by $28 \mathrm{~mm}$ long) was used. The diameter of the test specimens was measured using a venire caliper and the values recorded. The autographic recording drum was removed from the machine and covered with special graph paper then secured with long spring clip. The specimen was inserted in the Tensometer using split chucks and pins alignment was ensured. The mercury was adjusted to zero then the recording drum was adjusted to the suitable starting position ensuring that Perspex indicator set on zero and also the picker is set 
on the zero axis of the graph sheet. As the load was applied the extension was traced by following the mercury column with the sliding arm and depressing it to mark on the graph sheet at regular intervals till the specimen fail.

\subsection{Weight loss corrosion analysis}

The coupons used were cleansed and weighed. Sets of same concentration of simulated seawater were made, by providing a solution containing $3.5 \mathrm{~g}$ of $\mathrm{NaCl}$ in $100 \mathrm{~mL}$ of distilled water. The cleaned coupons were then immersed into the simulated seawater. The weight losses of the coupons were taken at interval of two days over a period of ten (10) days. The weight loss method of estimating the corrosion rate was employed. The weight loss was determined by finding the difference between the initial weights of the coupons and the final weight using the relationship.

$$
W=W 0-W f
$$

The corrosion rate was determined in mm per year ( $\mathrm{mm} / \mathrm{yr})$ using the relationship in [8].

$$
\text { Corrosion rate }=\frac{W}{D \times A \times T}
$$

In (1) and (2), W is the weight loss (mg), D is the density of the materials, $\mathrm{g} / \mathrm{cm}^{3}, \mathrm{~A}$ is the exposed surface area $\left(\mathrm{cm}^{2}\right), \mathrm{T}$ is the total time of immersion (hr), W0 is the initial weight of coupons, Wf is the final weight of coupons

\section{MICROSTRUCTURAL EXAMINATION}

Metallographic specimens were cut from the low temperature and control samples. The cut samples were then mounted in Bakelite and mechanically ground progressively on grades of $\mathrm{SiC}$ impregnated emery paper (80-600 grits) size using water as the coolant. The ground specimens were then polished using one-micron size alumina polishing powder suspended in distilled water. Final polish was done using 0.5-micron alumina polishing powder suspended in distilled water. Following the polishing operation, etching of the polished specimen was done using Kellers reagent and the micrographs obtained were then recorded using an optical microscope with built in camera and a Field Emission scanning electron microscope equipped with energy dispersive spectrometer (FE-SEM) with model: Joel JSM-7600F.

\section{RESULTS AND DISCUSSION}

\subsection{Hardness Measurement and Ageing Treatments}

From the Hardness results obtained, the control was 6.0 HRB while the highest value was obtained in the low temperature ageing of $90^{\circ} \mathrm{C}$ as $7.8 \mathrm{HRB}$.This can be deduced that low temperature ageing treatment have an appreciable influence on precipitation strengthening of this alloy.

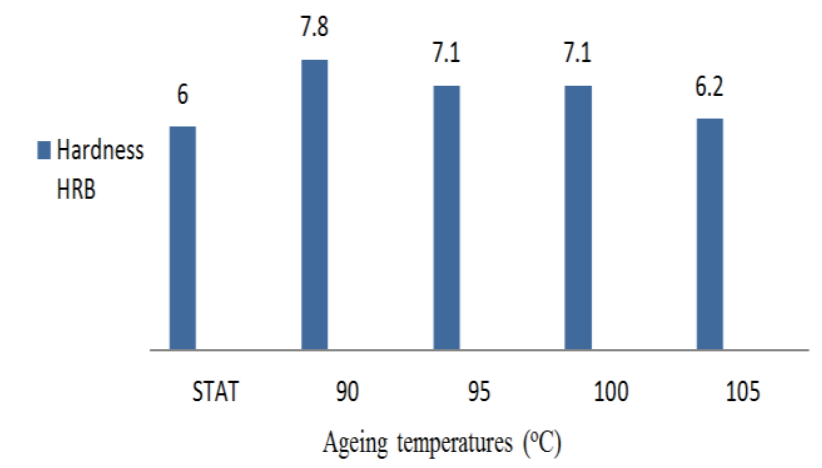

Figure 1: Variation of hardness under different condition of ageing

\subsection{Tensile Test Measurement and Ageing Treatment}

The extension value of the conventional ageing treatment was $1.4 \mathrm{~mm}$ as compared with the low temperature ageing treatment with the highest extension of $2.26 \mathrm{~mm}$ at $105^{\circ} \mathrm{C}$ of ageing. This also shows that low temperature ageing treatment has an appreciable influence on the ductility of this alloy

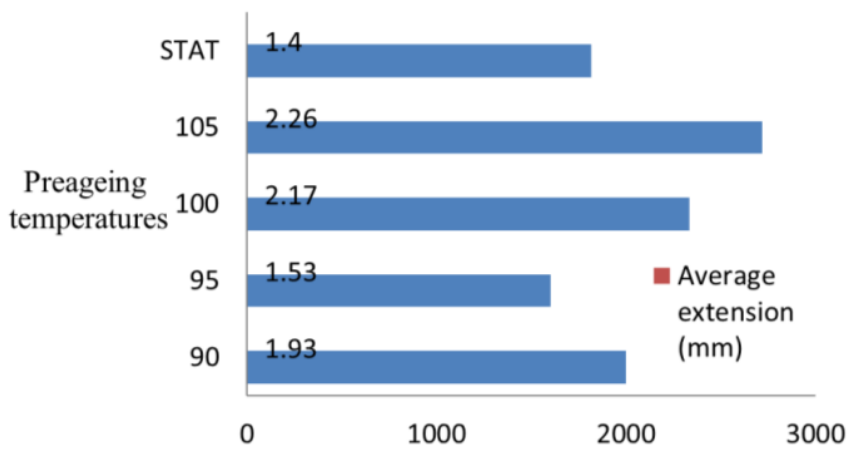

Figure 2: Average extensions at different low temperatures compared with STAT

\subsection{Relationship between microstructure and mechanical properties of $\mathrm{Al}-6.5 \% \mathrm{Si}-0.35 \% \mathrm{Mg}$}

The grain boundaries of the STAT were larger when compare with that of low temperature ageing. The close boundaries in the low temperature ageing sample show greater ductility, however the larger the boundaries the lesser the hardness. The reason could be as a result of the fact that any decrease in hardness may be associated with an increase in the interparticle spacing between precipitates, which makes dislocation bowing much easier. At peak hardness temperature, the microstructure might have been refined by heat treatment into a fine dispersion of possibly Al12Mg17 and Al3Mg7Si2 strengthening phases $[5-7,9]$ which is coherent along with the semicoherent clusters 


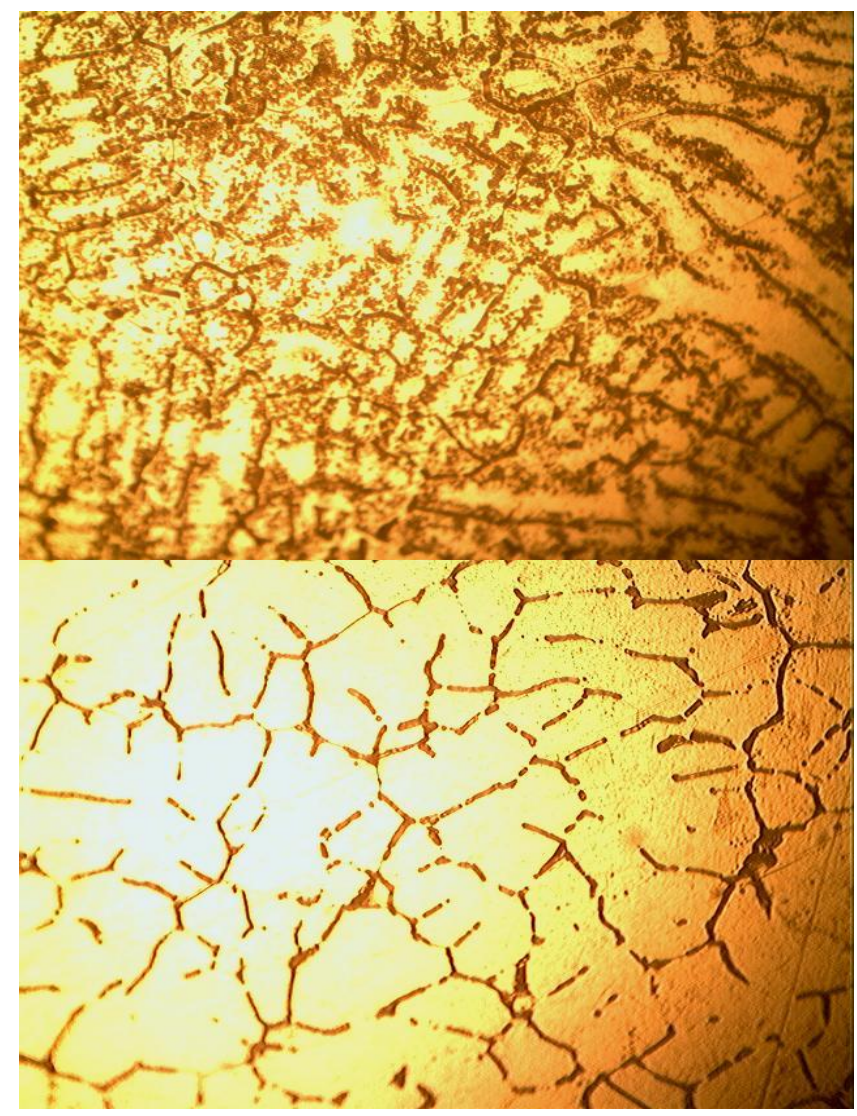

Plates 1: OPM Microstructure of Control and low temperature ageing of $90^{\circ} \mathrm{C}$ of $\mathrm{Al}-6.5 \% \mathrm{Si}-0.35 \% \mathrm{Mg}$ Alloy

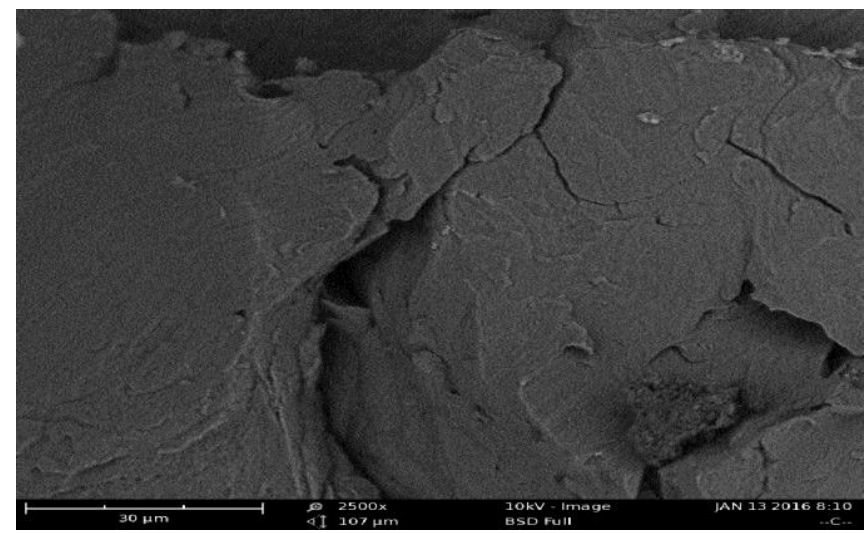

Plate2: SEM microstructure of control samples of AI$6.5 \%$ Si-0.35\%Mg Alloy

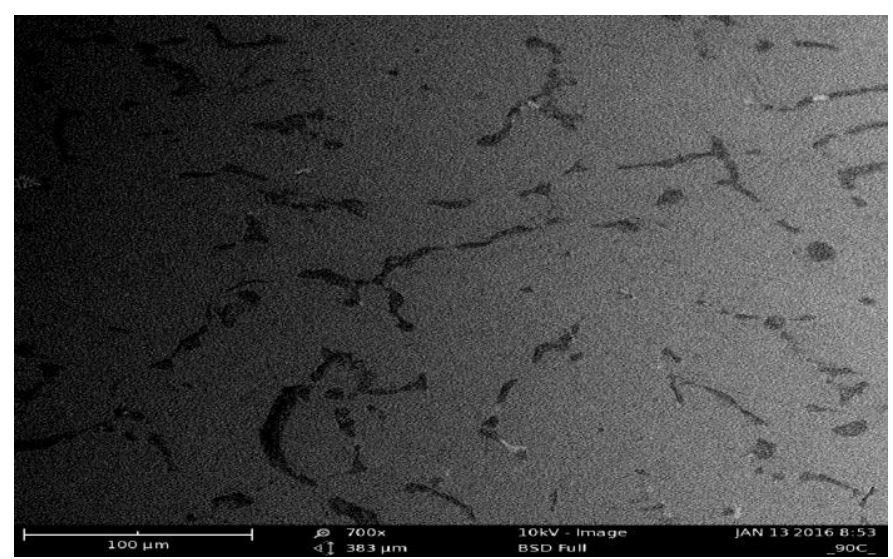

Plate3: SEM microstructure of low temperature ageing at $90^{\circ} \mathrm{C}$ ofAl-6.5\%Si-0.35\%Mg alloy
The alloy at this peak ageing temperature produces hardness value that may be attributed to formation of $\mathrm{Mg} 2 \mathrm{Si}$ and other strengthening phases as observed in $[5-7,9]$.The precipitation constituent as stated in[57] accounted for an increased in hardness, been that the eutectic Si transformed into spheroidized eutectic Si embedded among the homogeneous $\alpha$-Al matrix. The $\mathrm{Mg}_{2} \mathrm{Si}$ dispersoid phase is more refined, highly populated and distributed within the matrix of aluminum solid solution. These have been shown in the SEM image in (Plate 3). In the microstructure, it was clear that more fine precipitate of $\beta^{\prime \prime}$ dispersion occurred from the low temperature ageing of the alloy which is similar to those observed in $[7,9]$.This may be responsible for the improved hardness.

\subsection{Weight Loss Analysis of Al-6.5\%Si-0.35\%Mg alloy}

The corrosion rates of $\mathrm{Al}-6.5 \% \mathrm{Si}-0.35 \% \mathrm{Mg}$ alloy in various heat treatments are shown in Figure 3. From the results obtained, the control alloy has the highest corrosion rate. This implies that the corrosion susceptibility of this alloy is greatly influenced by the heat treatment. Also, low temperature ageing of $95^{\circ} \mathrm{C}$ demonstrated a remarkable decrease in the corrosion rate than the control.

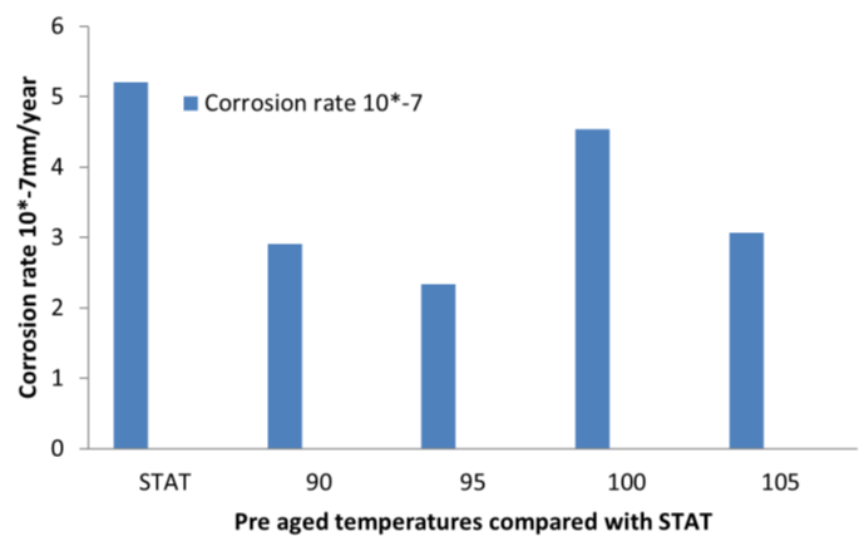

Figure 3: Corrosion under low temperature ageing compared with the control

\section{CONCLUSIONS}

In this research, the variation in low temperature ageing treatment conditions of Al- $6.5 \% \mathrm{Si}-0.35 \% \mathrm{Mg}$ alloy has greatly improved the properties of this alloy in the studied condition. In line with the above, the following conclusions are made;

1. Low temperature thermal treatment has been shown to be one of the possible ways of improving hardness, tensile and corrosion resistance of $\mathrm{Al}-$ $6.5 \% \mathrm{Si}-0.35 \% \mathrm{Mg}$ alloy within the studied conditions. 
2. The peak hardness value of $7.8 \mathrm{HRB}$ was achieved from low temperature treatment comprising of pre-ageing at $90^{\circ} \mathrm{C}$.

3. The improvement of hardness can be attributed to the finer dispersion of precipitates obtained as a result of low temperature ageing, which was further retained and fully transformed to finer particles at higher ageing temperature.

4. The results of tensile test on $\mathrm{Al}-6.5 \% \mathrm{Si}-0.35 \% \mathrm{Mg}$ alloy subjected to axial load has shown that the ductility of low temperature aged $\mathrm{Al}-6.5 \% \mathrm{Si}$ $0.35 \% \mathrm{Mg}$ alloy has been enhanced significantly as compared to those observed in the control condition.

5. Results from low temperature ageing of $105^{\circ} \mathrm{C}$ showed a better ductility as compared with the control Al-6.5\%Si-0.35\%Mg alloy.

6. The result obtained from weight loss method showed better corrosion resistance at low temperature ageing of $95^{\circ} \mathrm{C}$ when compared with the control.

\section{REFERENCES}

[1]. Leo, p., and Cerri, E. Silicon Particle Damage in a Thioxocast A356 Aluminum Alloy. Material Science and Technology: Teksid Aluminium Journal. 21(1) 27-31. 2003.

[2]. Hadley, S. W., Das, S., Miller, J. W. Aluminum Research and Development (R\&D) For Automotive uses and the Department Of Energy's Role. $R \& D$ Report/Findings for the Energy Division, Office Of Advanced Automotive Technologies US (ORNLTM 1999/152) 1-7. 2000.
[3]. Feng Wang, Jishon Zhang, Baiqing Xiong, Yongan Zhong, Effect of Iron (Fe) and Manganete ( $\mathrm{Mn}$ ) Addition on Microstructure And Mechanical Properties of Spray- Deposited Al-20Si-3Cu-1Mg Alloy. Journal of Material Character. 60, 384-388s 2009.

[4]. Haghshenans, M., Zarei-Hamzaki, A., FatemiVarzaneh, S. M. Effect of Thermo Mechanical Properties On The Microsructure of Thioxocast A356 Aluminium Alloy. Journal of material Science and Engineering. 480, 68-74. 2008.

[5]. Abdulwahab, M. Effect of Multiple-Step Thermal Ageing Treatment on the Hardness and Corrosion Characteristics of A356.0-Type Al-Si-Mg Alloy. (Unpublished Doctoral dissertation). Department of Metallurgical and Materials Engineering, Ahmadu Bello University, Zaria, Nigeria. 2011.

[6]. Umaru O. B, Effect of pre-ageing conditions on the hardness and corrosion characteristics of double thermally aged Al-Si-Mg alloy, (Unpublished Msc. dissertation). Department of Metallurgical and Materials Engineering, Ahmadu Bello University, Zaria, Nigeria. 2013.

[7]. Umaru 0. B, Abdulwahab. M, Yaro S. A, Asuke. F, Fayomi O. S. I, Influence of pre-ageing thermal condition on the corrosion characteristics of A356.0 type Al-Si-Mg alloy, International Conference on Sustainable Manufacturing and Operations Management, ISOM, University of Mauritius. pp 8692, 2013.

[8]. Li, Y. J., Brusethaug, S., Olsen, A. Influence of Cupper on the Mechanical Properties and Precipitation Behavior of AlSi7Mg0.5 Alloy during Ageing Treatment. Scripta Manterilia, 54, 99-103, 2006.

[9]. Leo, P., Cerri, E. Silicon Particle Damage in a Thixocast A356 Aluminium Alloy. 2003. 